\title{
Semenoma Originated from an Ectopic Testis
}

\author{
Otheman Fahsi ${ }^{1 *}$, Hafssa El Ouazani ${ }^{2}$, Adil Kallat ${ }^{1}$, Amine Kessab ${ }^{2}$, Hicham Ouazize ${ }^{1}$, Amine Slaoui ${ }^{1}$, Fouad \\ Zouaidia $^{2}$, Hachem El Sayegh ${ }^{1}$, Ali Iken ${ }^{1}$, Lounis Benslimane ${ }^{1}$ and Yassine Nouini ${ }^{1}$ \\ ${ }^{1}$ Department of Urology, Hospital Ibn Sina, Morocco \\ ${ }^{2}$ Department of Anatomic Pathology, Hospital Ibn Sina, Morocco
}

Submission: June 12, 2017; Published: July 27, 2017

*Corresponding author: Otheman Fahs, Department of Urology, Hospital Ibn Sina, CHU Rabat, Morocco, Email: othefahsi@gmail.com

\begin{abstract}
The authors report an observation of a metastatic seminoma on an ectopictesticle in a 23 years old patient and discuss the epidemiological, diagnostic, therapeutic and evolutionary aspects of this entity. Clinical diagnosisis often difficult due to the diversity of clinical symptoms, the use of imaging, biological markers and percutaneous biopsyis essential to make the diagnosis. The anatomopathology and therapeutic aspects are similar to the testis in normal situations. Early diagnosis of these tumors involves the lowering of the cryptorchid testicles, because even if this lowering does not prevent the setumors, it allows better monitoring.
\end{abstract}

Keywords: Ectopictesticle; Abdominal mass; Semenoma

\section{Introduction}

Abnormal testicular migration occurs in $2-5 \%$ of boys, with most cases unilateral (90\%). In $20 \%$ of cases the testicle is not palpable, of which $20 \%$ are absent [1]. Intra-abdominal localization is less frequent but has a higher risk of malignant degeneration compared to the testis in the inguinal canal. This risk of degeneration varies between 30 to $40 \%$ of cases and most are germ-celltumors; Semenoma being the most frequent [2].

\section{Case Report}

A young man of 23 years with out significant pathological history, has been present for 6 months bilateral low back pain especially on the left, progressive aggravation the whole evolving in a context of alteration of the general state. The clinical examination revealed a mass of the left iliac fossa fixed and sensitive, with a vacuity of the left purse making suspect a tumor on ectopic testicle. The right testicle was in place. The rest of the examination is unique.

The biological balance found: HCGt: 62.59 ui /ml, aFP: 3.91 ui /ml, and LDH: 839.4 ui /l

Abdominal ultra sound showed a mass of the left iliac fossa with left uretero-hydro nephrosis. The thoraco-abdominopelvic CT scan (Figure 1) demonstrated a left lateral-vesical mass of retro peritoneal extension tissue compatible with a malignan process on the ectopic testicle with a retro peritoneal abdominal lymph adomectomyencom passing large vessels and
A left uretero-hydronephrosis (Figure 2). Surgical exploration revealed a voluminous left lateral-vesical poly lobal testicular tumor. The anatomo pathological examination concluded in a seminome on ectopic testicle with invasion of the epididymis and infiltration of the albuginea without lympho-vascular invasion. The patient received just after 3 BEP cures (bleomycin, etoposide, cisplatin). The thoraco-abdomino-pelvic CT scan and tumor control markers were not shown to have residual mass.

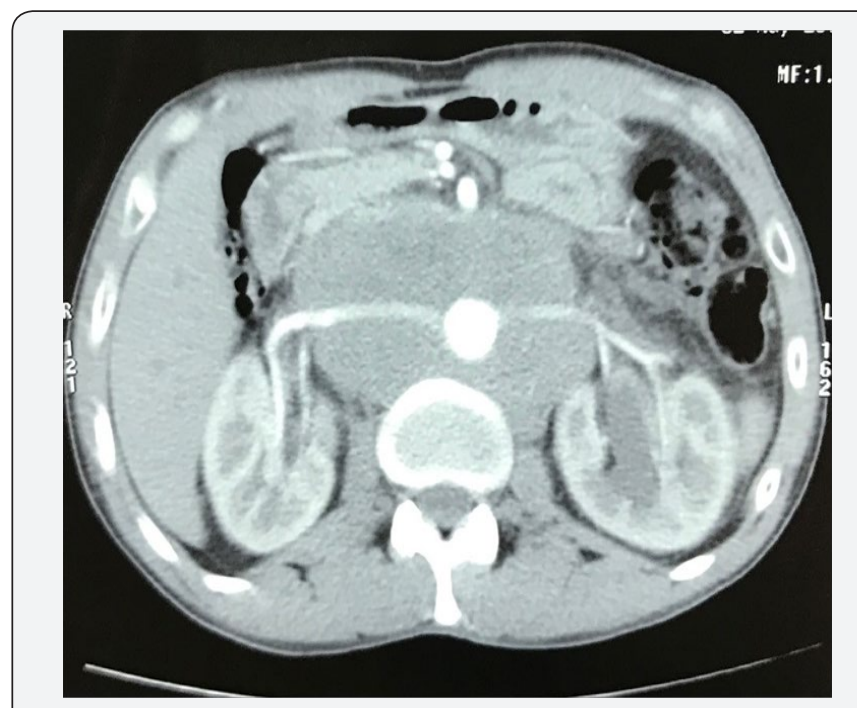

Figure 1: Left lateral-vesical mass of retroperitoneal compatible with a malignant process on the ectopictesticle. 


\section{Global Journal of Reproductive Medicine}

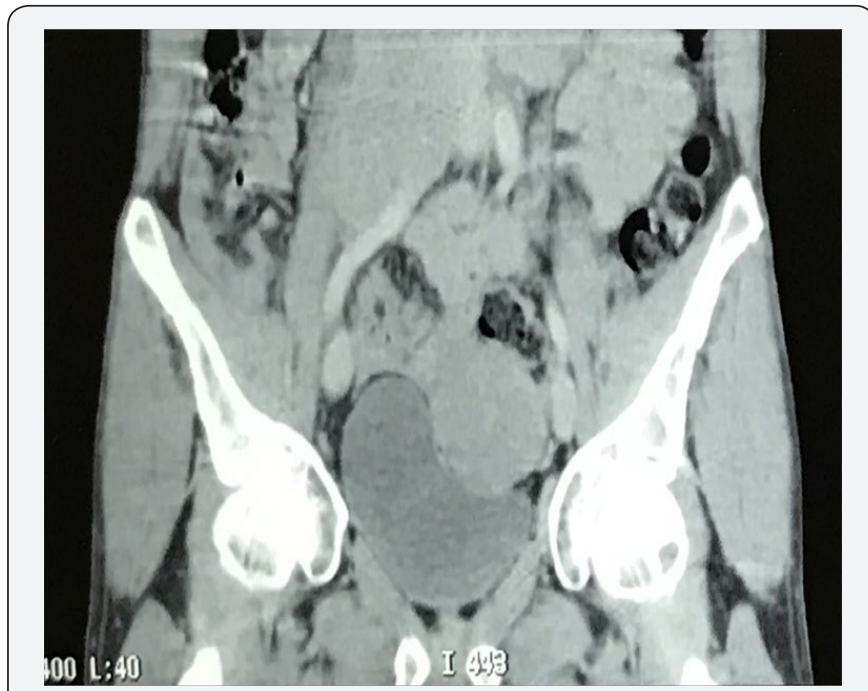

Figure 2: Retroperitoneal abdominal lymph adomecto myencom passing large vessels and A left uretero-hydro nephrosis.

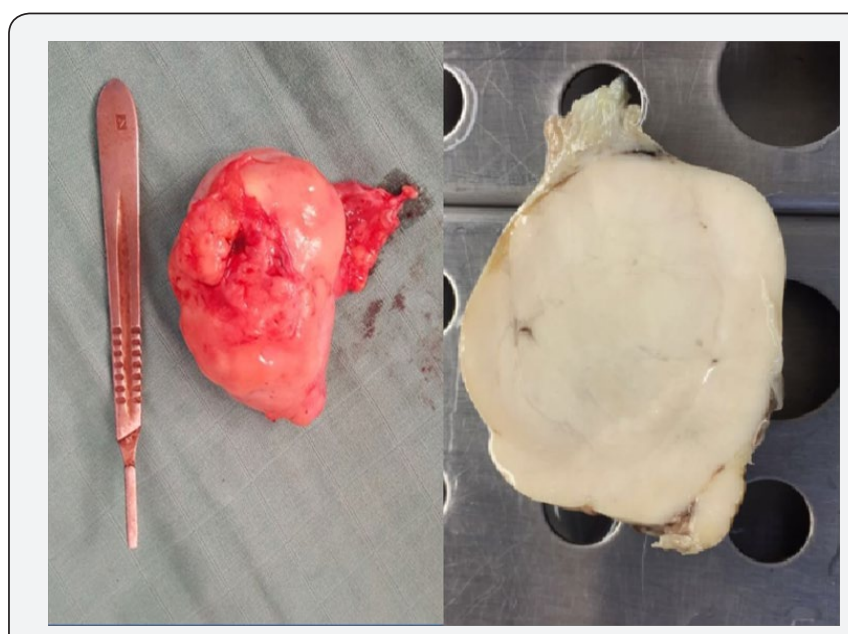

Figure 3: Surgical specimen and aspect macroscopique: Tumor of whitish appearance with invasion of the epididymis and infiltration of the albuginea.

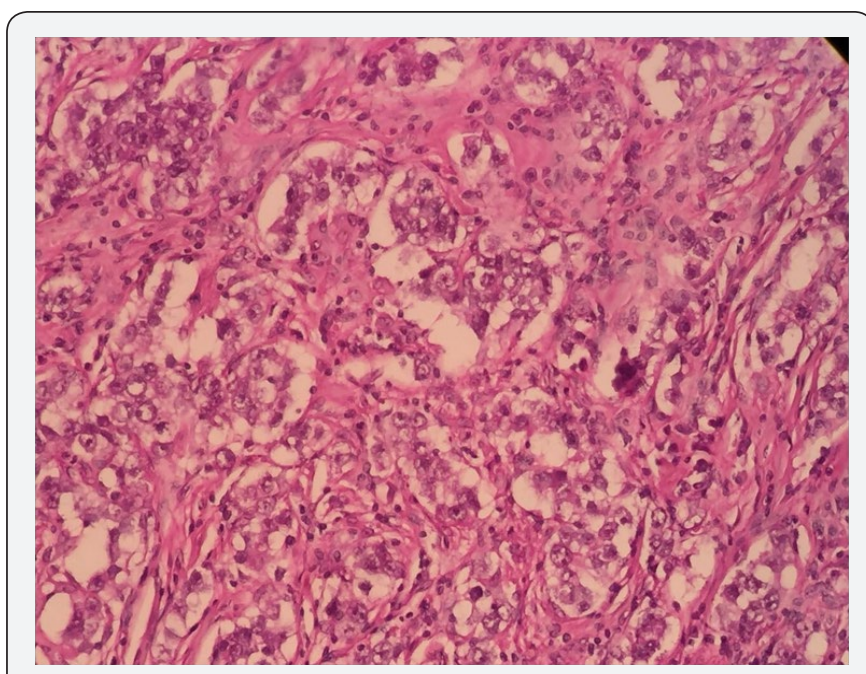

Figure 4: Aspect microscopique : embryonal cells with oval nuclei and clear cytoplasm and typical focal lymphocyte infiltrate.
Surgical exploration revealed a voluminous left lateral-vesical testicular tumor (Figure 3). The anatomo pathological (Figure 4) examination concluded in a seminome on ectopic testicle with invasion of the epididymis and infiltration of the albuginea without lympho-vascular invasion. The patient received just after 3 BEP cures (bleomycin, etoposide, cisplatin). The thoracoabdomino-pelvic CT scan and tumor control markers were not shown to have residual mass.

\section{Discussion}

Gerster described in 1897 the first case of torsion of an intraabdominal testicular tumor. It is an exceptionalevent. Nearly one in 500 men have an undescended testicle and some complications such as cancer, ischemia, infertility and torsion can be caused. Since the 1940's cryptorchidism and testicular germcel ltumors (TGCT) association has been well-documented. Because of the heat and other environmental insults on the gonads, the relative risk of developing TGCT is 3.7-7.5 times higher for a cryptorchid testis than normal intrascrotal testis [3]. That's why an abdominal testis presents a greater risk for TGCT than an inguinal testis [4]. Seminomais the most common single histologic type of germinal testicular neoplasms. Nevertheless $5-10 \%$ of testicular tumours occur in the contralateral, normally descended testis. Contrary to popular belief or chiopexy does not alter the malignant potential of the cryptorchid testis; Indeed, it only facilitates examination and tumour detection [5]. We describe three clinical stages for the extension of the tumour. In the first one the tumour is limited to the testis with or without invasion of epididymis or the spermatic cord. While for the second stage the tumour has retroperitoneal lymphnode metastases.

And finally with regard to the third Stage tumour has distant metastases. Seminoma has a high metastatic potential especially as it is highly predictable. Indeed, lymphatic metastases concern the retroperitoneal ganglia before an additional systemic implantation [6]. Finally, if the metastasis sites were to be classified in decreasing order of frequency, the retroperitoneal lymphnodes, the lungs, the liver, the mediastinal lymphnodes, the brain, the kidney, the gastro intestinal tract -intestinal, bones, adrenals, peritonoma and finally the spleen [7]. It is important to remember that unlike other germ cell tumors, the choriocarcinoma, is characterized by an early hematogenous spread. The main possible prognostic factors in the treatment of seminomas are age, tumor size, lymphovascular invasion, number of mitotics, necrosis, percentage of giant cell and tumour in filtrating lymphocytes [8].

Clinical presentations of intra-abdominal malignant testicles may range from asymptomatic mass to symptoms simulating an acute abdomen: appendicitis a strangulatedhernia. Sometimes it mimicsa simple urinary infection or dysuria by mass effect on a bladder or retroperitoneal heaviness [9].

The radiological and preoperative diagnosis of torsion of the intra-abdominal testicular tumor is rare and often difficult. 
Indeed, at the time of the anamnesis the cryptorchidiais not found and the imaging characteristic scan be non-specific. This is why mindful interrogation, thorough physical examination of the abdomen and genital organs, heed ful reading of radiological films and, above all, awareness of such complications badly lowered testicle. All this will improve diagnostic performance.

\section{Conclusion}

Any abdominal mass in a patient with a testicular migration abnormality, requires the clinician to suspect germ cell tumor regardless of the value of the tumor markers. A percutaneous biopsy may be indicated to prove the existence of germ cells. Only early diagnosis of undescended testicles and their lowering in the bursa make it possible to avoid such clinical forms.

\section{References}

1. González Méndez M, Solís Alfonso L, González López A, Ramírez Simono M (2010) Seminomatesticular intra abdominal. Reporte de un caso. Actas Urol Esp, pp.3

2. Alshyarba MH (2010) A gyant intra abdominal testicular seminoma. Biomedical research 21(3): 227-229.

his work is licensed under Creative Commons Attribution 4.0 Licens DOI: 10.19080/GJORM.2017.01.555572
3. Thorup J, McLachlan R, Cortes D, Nation TR, Balic A, et al. (2010) What is new in cryptorchidism and hypospadias - A critical review on the testicular dysgenesis hypothesis. J Pediatr Surg 45(10) : 2074-2086.

4. Cortes D, Thorup JM, Visfeldt J (2001) Cryptorchidism: Aspects of fertility and neoplasms. A study including data of 1,335 consecutive boys who under went testicular biopsy simultaneously with surgery for cryptorchidism. Horm Res 55(1): 21-27.

5. Canaklı F (2010) Cancer and Fertility: Long term Cryptos of Cryptorchidism. TurkUrol Sem pp 56-59.

6. Nguyen MM, Corr AS, Evans CP (2004) Testicular cancer metastaticexclusively to the brain and spleen. Urology 63(1): 176-178.

7. Johnson DE, Appelt G, Samuels ML, Luna M (1976) Metastases from testicular carcinoma. Study of 78 autopsied cases Urology 8(3): 234239.

8. Imaz AY, Bayraktar B, Sagiroglu J, Gucluer B (2011) Giant seminoma in an undescended testis presenting as an abdominal wall mass. J Surg Case Rep (12): 9.

9. Manisha M, Satyanarayana S, Anindita M, Rao KV, Rao GB (2009) Seminoma of undescended testis presenting as acute abdomen. Indian J PatholMicrobiol 52(2): 278-280.

\section{Your next submission with Juniper Publishers will reach you the below assets}

- Quality Editorial service

- Swift Peer Review

- Reprints availability

- E-prints Service

- Manuscript Podcast for convenient understanding

- Global attainment for your research

- Manuscript accessibility in different formats

( Pdf, E-pub, Full Text, Audio)

- Unceasing customer service

Track the below URL for one-step submission https://juniperpublishers.com/online-submission.php 